\title{
Deforestation and Water Borne Parasitic Zoonoses
}

\author{
Maria Anete Lallo \\ Universidade Paulista (UNIP), São Paulo \\ Brazil
}

\section{Introduction}

Disease emergence or re-emergence is often the consequence of the societal and technological change and manifests frequently in an unpredictable manner. It has been estimated that among emerging diseases, $75 \%$ has zoonotic characteristics. Many factors influencing the emergence of zoonoses, such as environmental change and land use, changes in demographics, changes in technology and industry, increasing international travel and commerce, breakdown of public health measures, and microbial adaptation and change (Broglia \& Kapel, 2011).

Deforestation is one of the most disruptive changes affecting parasitic and vector populations. When the forest is cleared and erosion of the soil strips away the former state, if indeed, it is permitted and able to regenerate. The response of tropical forests to perturbation is affected by soil type, elevation, mean precipitation, and latitude. Cleared tropical forests are typically converted into grazing land for cattle, small-scale agricultural plots, human settlements or, left as open areas. Expansion of existing human settlements and movement of human populations create a need for increased food supply, leading to changes in the types and amounts of vegetation, thereby providing changed ecological niches and conditions for proliferation of newly arriving and/ or adaptive existing vectors and their parasites (Slifko et al., 2000). Deforestation is one of the changes that most affect the ecological niches of the disease, favoring the transmission of them (Patz et al., 2000; Slifko et al., 2000).

The waterborne or food is the main route of transmission of parasitic diseases. Zoonoses such as giardiasis, cryptosporidiosis and microsporidiosis are waterborne diseases that include the participation of domestic and wild animals and man. Environmental changes and ecological disturbances, due to both natural phenomena and human intervention, have exerted and can be expected to continue to exert a marked influence on the emergence and proliferation of zoonotic parasitic diseases. They change the ecological balance the ecological balance and context within which vectors and their parasites breed, develop, and transmit disease (Patz et al, 2000).

Interest in the contamination of drinking water by enteric pathogenic protozoa has increased considerably during the past three decades and a number of protozoan parasitic infections of humans are transmitted by the waterborne route (Patz et al., 2000; Slifko et al., 2000). 
Waterborne transmission is one of the main risk factors for intestinal diseases causing an important morbidity and mortality worldwide. Over $50 \%$ of the waterborne infections are produced by unknown agents. In the last years, for economic and environmental reasons, spreading sewage sludge on agricultural lands has increased. This might affect not only the circulation of recognized pathogens such as Cryptosporidium and Giardia, but also emerging pathogens, such as microsporidia. The general impression is that treatment of water has demonstrated a high efficacy of pathogen removal, however, as viable pathogen have been detected in water. It is important understand that the presence of human pathogens in surface water may suggest the presence of living environmental reservoirs, such as domestic and wild animals. Aquatic birds may play an important role in the transmission of different pathogens (Izquierdo et al., 2011).

The parasites Cryptosporidium, Giardia e microsporidia are major of diarrheal disease in human, worldwide and have also been recognized as the predominat causes of waterborne diseases. Cryptosporidium, Giardia and microsporidia have life cycle wich are suited to waterborne and foodborne transmission. Their life cycle are completed within and individual host, with transmission by fecal-oral route. The transmissible stages, Cryptosporidium oocysts or Giardia cysts or microsporidia spores, are produced in a large numbers and are infectious when excreted, a marked resistence to environmental and water treatment stresses, wich assists their dissemination, and have the potential to be transmitted from non-human to human hosts (zoonoses) and vice-versa, enhancing the reservoir of (oo)cysts or spores markedly (Smith et al, 2007). The purpose of this chapter is to show the biological and epidemiological aspects most relevant of the parasites Cryptosporidium, Giardia and microsporidia responsible for waterborne parasitic diseases most important.

\section{Cryptosporidiosis}

It is a parasitic disease caused by protozoa of the genus Cryptosporidium, which affects amphibians, birds, mammals, reptiles and fish and is characterized by impairment of the digestive system. Since its first description in the 1970s, cryptosporidiosis has been considered an opportunistic infection in immunodeficient individuals, it is known today, however, that it is a prevalent disease in immunocompetent individuals also important. Many studies have also revealed the prevalence of this protozoan infection in animals, although the zoonotic transmission of the disease is not yet fully understood (Fayer et al., 2010).

\subsection{About the agent and the disease}

Cryptosporidium is a protozoan that has about 22 identified species (Table 1). Although many species have been described to date, C. parvum is the most widespread species of mammals, including man. It is known that $C$. paroum is not a homogeneous species since the isoenzyme analysis and DNA sequencing revealed differences between oocysts isolated from various animal species. 7 genotypes have been identified - of cattle, humans, mice, pigs, opossuns, dogs and ferrets (Fayer 2010; Plutzer Karanis, 2009).

As in other coccidian monoxenic its life cycle is not employing intermediate host. Cryptospodirium oocysts are small and contain four sporozoites inside free. When they are ingested by the host, the oocysts release of sporozoites in the small intestine, which invade intestinal cells. The sporozoites begin multiplying to form asexual meront type I and type II 
with 4 and 8 merozoites, respectively. The type II merozoites give rise to the sexual phase of the cycle or gametogony with differentiation stages in male (microgametes) and female (macrogametes). The microgametes penetrates macrogamete leading to the formation of a zygote that develops into oocyst. Are two types of oocysts produced - a kind of thin-walled autoinfectante able to release within the host, starting a new cycle and a thick-walled, highly resistant to environmental conditions, which is eliminated in feces. The cycle time is variable and may occur in up to 48 hours or 14 days depending on the host species. Unlike other coccidia, which eliminate the non-sporulated oocysts, the oocysts of $C$. paroum undergo sporulation within the host, eliminating the already infective for the environment (Carey, 2004; Chalmers \& Davies, 2009).

\begin{tabular}{ll}
\hline Species & Hosts \\
\hline & Fishes \\
\hline Psicicryptosporidium cichlidis & Oreochromis miloticus e Tilapia zilli \\
Psicicryptosporidium reichenbachklinkei & Trichogaster leeri \\
Cryptosporidium molnari & Sparus auratusDicentrarchus labrax (Gilthead) \\
C.scophthalmi & Scophthalmus maximus(Turbot) \\
\hline & Amphibians and reptiles \\
\hline C. serpentis & Elaphe guttata (Corn snake) \\
C. varanii & Varanus prasinus (Emerald monitor) \\
C. fragile & Duttaphrynus melanostictus (Black-spined toad) \\
\hline & Birds \\
\hline C. meleagridis & Meleagris gallopavo (turkey) \\
C. baileyi & Gallus gallus (chicken) \\
C. galli & Gallus gallus (chicken) \\
\hline & Mammals \\
\hline C. muris & Mus musculus (mice) \\
C. parvum & Mus musculus (mice) \\
C. wrairi & Cavia porcellus (guinea pig) \\
C. felis & Felis catis (cat) \\
C. andersoni & Bos taurus (cattle) \\
C. canis & Canis familiaris (dog) \\
C. hominis & Homo sapiens (man) \\
C. suis & Sus scrofa (pig) \\
C. bovis & Bos taurus (cattle) \\
C. fayeri & Macropus rufus (kangaroo) \\
C. ryanae & Bos taurus (cattle) \\
C. macropodum & Macropus giganteus (kangaroo) \\
\hline
\end{tabular}

Table 1. Species of Cryptosporidium by Fayer (2010).

The pathogenesis and clinical picture of criptoporidiose are influenced by several factors, including animal species, age, immune response and association with other pathogens. The infection can range from subclinical to severe, And have more severe disease (Table 2). In humans, the incubation period is 20-10 days and the duration of the disease in immunocompetent individuals, up to 3 weeks. In immunodeficient or immunosuppressed individuals, infection is chronic, with symptoms and elimination of persistent oocysts. The 
clinical signs manifested in cryptosporidiosis include profuse watery diarrhea, vomiting, anorexia, weight loss, abdominal pain, fever and dehydration. In immunocompetent individuals, these symptoms are mild and transient. The spread of infection to the gallbladder and bile ducts, pancreas and respiratory system is common in AIDS patients (Barr, 1998; Chalmers \& davies, 2009).

The diagnosis of cryptosporidiosis is based on the meeting of the parasite in feces, using methods of concentration of oocysts, such as formaldehyde or ether flotation with saturated sucrose solution, associated with staining techniques, such as Ziehl- Nielsen, Kinyoun, fuchsin or safranin. Different immunological techniques have been used for the diagnosis of human cryptosporidiosis. Among them, ELISA or immunofluorescence with monoclonal or polyclonal antibodies are used to detect oocysts in the feces. The PCR technique is an alternative to both conventional diagnosis of Cryptosporidium in fecal specimens and in environmental samples. Although PCR is rapid, sensitive and accurate, has limitations as the detection of nucleic acid of viable organisms, naked nucleic acid and the possibility of laboratory contamination. We recommend its use for oocysts in water samples (Fayer et al., 2000; Marquardt et al., 2000; Xiao, 2002).

\begin{tabular}{|c|c|c|}
\hline Characteristics & Immunodeficient individuals & $\begin{array}{l}\text { Immunocompetent } \\
\text { individuals }\end{array}$ \\
\hline Susceptible population & $\begin{array}{l}\text { Immunocompromised persons } \\
\text { of all ages, especially with AIDS }\end{array}$ & $\begin{array}{l}\text { Children, first with less than } \\
1 \text { year of age and adults of all } \\
\text { ages }\end{array}$ \\
\hline Infection sites & Intestinal or extraintestinal & Intestinal usually \\
\hline Enteric form & $\begin{array}{l}\text { Asymptomatic or transient or } \\
\text { chronic diarrhea or fulminant }\end{array}$ & $\begin{array}{l}\text { Asymptomatic, acute and } \\
\text { persistent }\end{array}$ \\
\hline Clinic form & $\begin{array}{l}\text { Diarrhea, fever, abdominal pain, } \\
\text { weight loss e vômitos }\end{array}$ & $\begin{array}{l}\text { Diarrhea, fever, abdominal } \\
\text { cramps, weight loss, nausea } \\
\text { and vomiting }\end{array}$ \\
\hline
\end{tabular}

Table 2. Characteristics of cryptosporidiosis in humans.

\subsection{Epidemiology and prophylaxis}

Cross-transmission studies revealed that oocysts obtained from humans are infective to other mammals, as oocysts from animals that are infectious to other species, it is a zoonotic disease potential. The epidemiology of cryptosporidiosis is influenced by the capacity of thick-walled oocysts survive in the environment (Table 3) (Xiao, 2002).

\begin{tabular}{ll}
\hline Temperature & Survival Time \\
\hline 25 e $30^{\circ} \mathrm{C}$ & 3 months \\
$20^{\circ} \mathrm{C}$ & 6 months \\
$15^{\circ} \mathrm{C}$ & 7 months \\
-20 e $-70^{\circ} \mathrm{C}$ & Feel hours \\
\hline
\end{tabular}

Table 3. Survivel condition of Cryptosporidium oocysts

The oocyst is the oral-fecal route and occurs until now, have been described various forms of transmission, can be highlighted - from person to person by direct or indirect contact, 
including sexual activities, from animal to animal, animal to man, by drinking water or recreation, from food and air. The number of oocysts required to establish an infection is small, it is estimated that the infectious dose varies from 9 to 1,000 oocysts (Fayer et al., 2010).

Feces containing oocysts contaminate soil, food and water. The movement of oocysts in the environment is favored by the winds, the rain water, the movement of animals and the actions of man himself. The major outbreaks of cryptosporidiosis reported in HIV-negative people are linked to the ingestion of water contaminated with oocysts derived from cattle or sheep. This water containing oocysts also contaminated foods, especially vegetables and fruits, and is another important way of transmission in outbreaks of cryptosporidiosis. Additionally, food can be contaminated by the hands of manipulators (Robinson et al., 2010).

A variety of risk factors are associated with infection by Cryptosporidium, among them stand out from the deficiency of the immune response, the presence of concomitant infections, ingestion of contaminated food and water, poor sanitary conditions and occupational exposure, is the contact with animals or infected humans (Plutzer et al., 2009).

From the earliest descriptions of cryptosporidiosis in humans, the number of cases has continued to grow, in the case of individual reports or outbreaks, such infection is attributed to C. paroum. The average prevalence in industrialized countries by $2.2 \%$ in immunocompetent individuals and $14 \%$ in HIV-positive. Already in developing countries, these numbers increase and may reach $8.5 \%$ in immunocompetent patients and $24 \%$ in HIV-positive. This means that proper sanitary conditions and a rigorous treatment of the water, as seen in developed countries, the spread of the disease can be decreased (Hajdušek et al., 2004).

In the United States, an estimated $50 \%$ of the animals from cattle herds eliminate oocysts of C. paroum, however, the disease is preferentially observed in calves that manifest from the 4th day of life until the fourth week. In other domestic animals, the prevalence of cryptosporidiosis is less valued, however it is known that predominates in neonates and young people (Thompson et al., 2009).

Human or animal cryptosporidiosis can only be controlled if the oocysts of the parasite is eliminated or destroyed. The oocysts can spread and persist in the environment for a long time. Moreover, it is known that this parasitic form also resists water to conventional treatments such as chlorination and filtration. Giardia is 14 to 30 times more susceptible to water treatment with chlorine or ozone. Either way, ozone is the most effective chemical agent in the inactivation of Cryptosporidium oocysts (Thompson et al., 2008).

To reduce the risk of infection of individuals more susceptible to cryptosporidiosis, such as HIV-positive, immunosuppressed individuals and children, it is recommended that drinking water be boiled for about 1 minute before ingestion. The same recommendation should be made for the young or immunodeficient animals (Fayer et al., 2010; Thompson et al., 2008).

Others include general health care and proper cleaning of the hands of food handlers, proper disposal of animal waste, sewage treatment, washing litter boxes with boiling water, among others (Chalmers \& Davies, 2009).

One should keep susceptible individuals, HIV-positive or immunosuppressed, have contact with the feces of pets, especially if they have less than 6 months old. If this is not possible, you should recommend the appropriate use of gloves. Not recommended the removal of this person's contact with your pet because of the strong emotional bond that unites them. Immunosuppressed patients should ideally acquire an animal older than 6 months, you do not have diarrhea and it has been previously examined by a veterinarian (Fayer et al, 2000; Xiao, 2010). 
Of the various species of Cryptosporidium, C. parvum has been observed in a larger number of human infections, and reaches a large number of animal species. Within this species, two genotypes are, most of the time, described the infection - the human (38\% of infections) and cattle (62\% of infections). Thus, for the human cryptosporidiosis occurring bovine genotype is necessary to contact with infected animals such as cattle, sheep and goats, or that there is environmental contamination, especially water and food. Several cases of cryptosporidiosis have been reported in veterinary students and animal handlers, resulting probably from contact with infected animals, especially cattle, which reinforces the possibility of such transmission. Recently, the dog genotype of C. paroum has also been identified in human infections(Fayer et al, 2000; Xiao, 2010).

All these evidences indicate that a large number of hosts and genotypes may be involved in cryptosporidiosis and molecular characterization of this parasite should facilitate understanding of the epidemiology of the disease. While these points are not completely understood, it is recommended the adoption of control measures in situations of potential risk (Xiao, 2010).

\section{Giardiasis}

It is a disease caused by the flagellate protozoan Giardia, intestinal parasite of a wide variety of animals, including man, constituting one of the most prevalent intestinal parasites, known and described throughout the world (Marquardt et al.,2000).

\subsection{About the agent and the disease}

The most accepted classification of the genus Giardia is based on its morphological characteristics, with six described species - G. agilis, G. Muris, G. psittaci, G. ardeae, G. microti and G. duodenalis (Table 4). G. duodenalis is also known as G. intestinalis or G. lamblia. This protozoan has two simple forms of life - the trophozoite and cyst. The trophozoite lives in the small intestine where they act by the scourges, but many are adhering to the intestinal mucosa. The cyst is ovoid and is surrounded by a proteinaceous fibrous wall that confers resistance to the environment conditions (Hopkins et al., 1997; Volotão et al, 2007).

Giardia has a direct life cycle and its transmission is oro-faecal route. Drinking water contaminated with cysts represents a major cause of giardiasis in humans and other animals, which is therefore considered a waterborne disease (Kulda \& Nohýnková, 1995).

Inside the host, the cyst release two trophozoites that attach to the small intestine. The trophozoites start their asexual multiplication by binary fission and by action of bile salts and alkaline $\mathrm{pH}$ suffer encystment, but the mechanism and where this occurs remain unknown (Bogitsh \& Cheng, 1998).

Giardiasis may present as an asymptomatic or symptomatic, Acute or chronic disease. In adult animals, the infection is usually asymptomatic and is rarely detected. Already in young animals aged less than one year, clinical signs and symptoms may be present and identification of the parasite is more easily obtained (Thompson, 2000).

In general, clinical signs and symptoms observed in giardiasis include diarrhea, acute or chronic, steatorrhea, abdominal pain, lethargy, anorexia, flatulence, fatigue, abdominal distension, nausea, mucus in stools, growth deficits and weight loss (Bogitsh \& Cheng, 1998). 
The elimination intermittent cysts and lack of specific clinical signs makes the diagnosis of Giardia more difficult and requires multiple fecal examinations are carried out within 4 to 5 days (Kulda \& Nohýnková, 1995).

\begin{tabular}{ll}
\hline Species and genotypes & Hosts \\
\hline G. microti & Muskrat and voles \\
G. agilis & Amphibians \\
G. muris & Rodents \\
G. psittaci & Birds \\
G. ardeae & Birds \\
G. duodenalis (G. intestinalis ou G. & Mammals \\
lamblia) & \\
Genotypes of G. duodenalis & Humans, primates, dogs, cats, cattle, rodents, wild \\
Genotype A & animals \\
Genotype B & Humans, primates, dogs, horse, cattle \\
Genotype C & Dogs \\
Genotype D & Dogs \\
Genotype E & Ungulates \\
Genotype F & Cats \\
Genotype G & Rodents \\
\hline
\end{tabular}

Table 4. Species and genotypes of Giardia.

Techniques that promote the fluctuation of the cysts, using saturated solutions of zinc sulphate and sugar, are methods that allow diagnosis of most cases. Another method of diagnosis is an ELISA assay, which detects Giardia antigen in faeces preserved in formalin or kept under refrigeration. In humans, the sensitivity and specificity of this test is high $(100 \%$ and $96 \%$, respectively), allowing quick diagnosis, however, its use in dogs and cats revealed similar results flotation techniques, which are preferred for their low cost and ease of implementation. The indirect immunofluorescence and polymerase chain reaction (PCR) have been used for epidemiological studies or as research tools (Kulda \& Nohýnková, 1995).

\subsection{Epidemiology and prophylaxis}

Giardiasis is spread throughout the world being described more than 250 million symptomatic cases in humans for years and is now included as the list of neglected diseases made by the World Health Organization in humans, its prevalence depends on the level of hygiene and sanitary facilities, ranging from $2 \%$ to $43 \%$. Children are more susceptible to infection because of its low immunity and their lack of hygiene. In adults, infection may provide a certain degree of resistance to subsequent infections, reducing its prevalence in this age group (Mohammed Mahdy et al, 2008; Monis \&Thompson, 2003).

Although giardiasis is classified as a zoonosis by the World Health Organization, it is unclear the exact participation of animals in the epidemiological chain of transmission of this disease. However one must consider that the interaction of multiple hosts associated with environmental conditions are essential links to propitiate the occurrence of giardiasis, which just as cryptosporidiosis, are the waterborne disease (Mohammed Mahdy et al, 2008; Monis \&Thompson, 2003). 
Of all the species of Giardia only G. duodenalis has been observed in humans, livestock and pets. Many of these animals possess a particular genotype, but they all have infections with genotypes $\mathrm{A}$ and $\mathrm{B}$ also found in humans. The number of molecular studies involving the infection observed in man with concomitant infections in animals is very restricted in aboriginal Australians were detected 13 human cases and 9 dogs in the genotype A, as found cases of giardiasis by genotypes A and B simultaneously in dogs and humans in Bangkok. Some wild animals such as beavers and rats, which have a high prevalence of giardiasis by genotype B, has historically been considered important sources of water contamination (Cacció \& Ryan 2008).

The intake of only 10 cysts of Giardia is sufficient to determine the disease and an infected person can eliminate up to 300 million cysts per $\mathrm{ml}$ of feces (Inpankaew et al, 2007).

The infection is acquired by ingesting contaminated food or water. Cysts remain viable for weeks in water, which facilitates its transmission. The survival of cysts in the water the same temperature dependent and may remain viable for up to 2 months in water at $8{ }^{\circ} \mathrm{C}$ and for only 4 hours in water at $37^{\circ} \mathrm{C}$ (Xiao \& Fayer, 2008).

Water contamination is through human sewage or feces from infected animals. The occurrence of giardiasis in sparsely populated areas, such as the Arctic region of Canada, reinforces the hypothesis that wild animals such as beavers, constitute important sources of infection. The beavers have $44 \%$ prevalence of Giardia and therefore are reservoirs for human infection. As the transmission of this disease occurs by contamination of water, food and environment as described in Table 5, the prevention of giardiasis include environmental sanitation (Hunter \&Thompson, 2005).

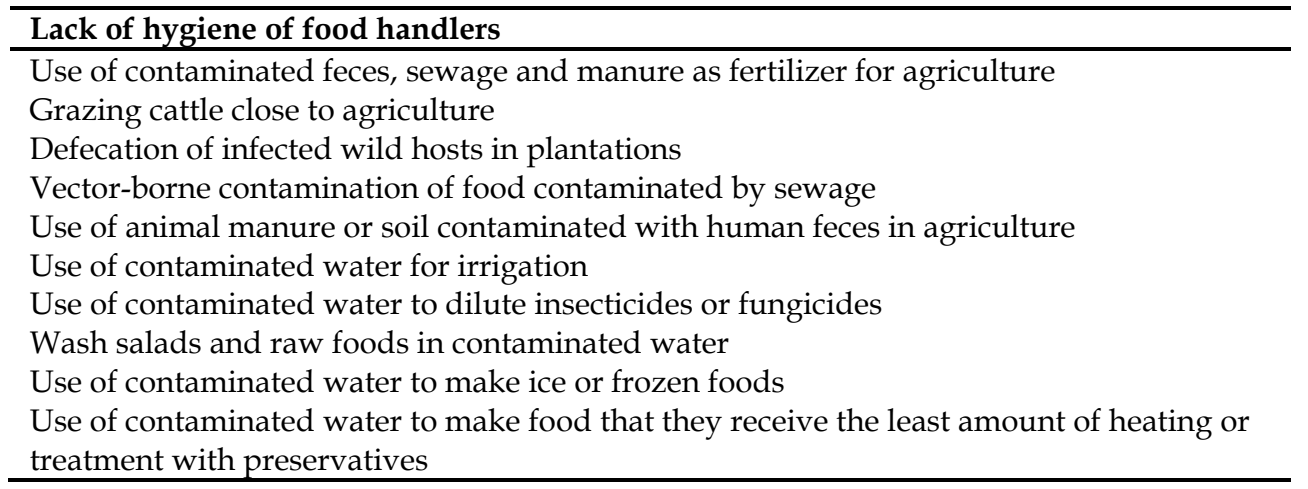

Table 5. Possible sources of food contamination.

The water should be protected from possible contamination by proper disposal and treatment of sewage from humans or animals. Because Giardia is resistant to routine chlorination of water, it is recommended that the flocculation, sedimentation and filtration of water are carried out before use. When the water is not subjected to such treatment, there should be boiling water, which promotes the complete removal of Giardia cysts. The greatest risk of zoonotic transmission is related to the genotype of G. duodenalis, which has been described in humans, farm animals, dogs, cats, beavers and in rodents (Hunter \& Thompson, 2005; Jerlström-Hultqvist, 2010). 
Farm animals, especially cattle, are an important source of infection for man. Cattle with giardiasis can eliminate up to one million cysts per gram of feces, so few infected animals are a major risk to public health (Thompson et al, 2008).

Although the clinical consequences of infection with Giardia in dogs and cats seem to be minimal, there are grounds for believing that such animals are important sources of infection in urban areas. Molecular epidemiology studies have shown that some genotypes are closely related to the infection in humans and dogs (Smith et al., 2007).

\section{Microsporidiosis}

Microsporidia are small eukaryotic intracellular parasites considered to be true, due to the presence of nuclear envelope coated core of intracytoplasmic membrane systems and separation of chromosomes by mitotic spindle. However, these protozoa also possess characteristics of prokaryotes, as a small ribosomal RNA (rRNA) and the absence of mitocrôndrias, peroxisomes and Golgi cisterns. These indicators point to the fact that they are phylogenetically very primitive protozoa, however, molecular studies reveal a close proximity of this group of parasites with the fungi, a fact that still causes doubts in the classification of these parasites. Diarrhea is the most frequent health problem caused, mainly in immunocomopromised people. The transmission routes indicated are via airborne, person-to-person, zoonotic, and waterborne means (Didier, 2005; Theiller, Breton, 2008).

\subsection{About the agent and the disease}

The life cycle of microsporidia includes three distinct phases: the spores responsible for transmission of infection, the proliferation of vegetative forms of intracellular schizogony or merogony calls, and finally the formation of spores or sporogony (Mathis, 2000).

The spores are very resistant structures to environmental conditions in its interior is an extrusion apparatus (polar tubule), whose function is to inject the infective material (sporoplasm) into the host cell. In the presence of favorable conditions, the extruded polar tubule and enters the host cell to inoculate sporoplasm in the cytoplasm of the same. The sporoplasm injected into the host cell starts proliferation merogony stage. His rapid multiplication occurs by binary or multiple fission. Then sporogony begins when meront acquire a dense amorphous layer around the cell, being called sporonts. These again can grow and multiply by binary or multiple fission sporoblasts to form, which, in turn, develop distinct cytoplasmic organelles and a thick wall, making the spores mature. The spores spread through the tissues of the host by infecting new cells and continuing the cycle (Mathis, 2000; Weiser, 2005).

So far, no evidence of intermediate hosts or vectors of microsporidial infection in man. For some genera that infect mosquitoes, has been reported a complex sequence of development, involving alternation between different invertebrate hosts (Weber et al., 2002).

The development of some species of microsporidia can be confined to cells of a single organ. However, other species can cause systemic infection. The clinical manifestations of infection are dependent on the species infected and the competence of the host immune response. The imbalance in the parasite-host relationship results in the proliferation and spread, causing cell destruction (Didier, 2005).

So far have been described about 1000 species of microsporidia belonging to 100 genera, however, this number will increase as new hosts are being researched. In humans, the infection was first described by Matsubayashi et al. in 1959 and since then an increasing 
number of cases have been reported particularly in immunocompromised individuals. The clinical manifestations include ocular lesions (conjunctivitis, chorioretinitis), muscles (myositis), kidney (nephritis), neurological (encephalitis), liver (hepatitis), peritoneal (peritonitis) and others (Abreu-Costa, 2005; Lallo et al., 2002; Lallo \& Bondan, 2005; Weber et al., 2002).

Some species of microsporidia infecting invertebrates and can cause serious economic losses. Two well-known examples are the Bombyx mori, which affects the creations of silkworm and Nosema apis, which infects bees and honey production decreases. On the other hand, some species are used in biological control of some pests, for example, Nosema locustae used to control locusts (Mathis, 2000; Méténier \& Vivarès, 2001).

More than 60 species, 11 genera of microsporidia have been described in fish. The most important genera are: Glugea, Pleistophora and Sprague. In freshwater fish and saltwater, the infection is highly contagious and can be fatal, the parasite is found in the intestine, bile ducts, liver, mesenteric lymph nodes, nerve ganglia, in the subcutaneous tissue, testes and ovaries (Rodriguez-Tovar et al.,2011).

We found cysts of Giardia were found in faecal samples from 2 prehensile-tailed porcupines (Coendou villosus) and Cryptoporidium oocysts in 3 rodents - montane akodont (Akodon montensis), ebony akodont (Thaptomyces nigrita) and guainan squirrel (Sciurus aestuans). Microporidia spores were seen in the stools of small rodents, including 3 montane akodonts, 1 prehensile-tailed porcupine and 2 pigmy rice rats (Oligoryzomys sp.), as well as of 3 marsupials, including 1 gray slender mouse opossum (Marmosops incanus) and 1 big eared opossums (Didelphis aurita), and of 3 hairy-legged vampire bats (Diphylla ecaudata). This was the first description of microsporidiosis in wildlife animals in Brazil. The study emphasizes the importance of the animals, particularly small wild mammals, as potential sources of parasite infection to other animal populations, including man, in areas of deforestation (Lallo et al. 2009; Pereira et al. 2009).

Few cases of human microsporidiosis had been reported until the advent of AIDS. However, it is now considered emerging and cosmopolitan. Among the species that cause human microsporidiosis, E. bieneusi is responsible for most infections occurring in approximately $40 \%$ of AIDS patients who have chronic diarrhea. It is not clear, however, what the risk factors that may be related to the prevalence of infection. Most reports occur in male patients, HIV-positive and CD4+ lymphocyte count at or below 100 cells/mm3, with few cases observed in women and children (Malčekova, 2010).

\subsection{Epidemiology and prophylaxis}

There is much controversy about the mechanisms of transmission of microsporidia. It is believed that the ingestion of spores is an important route for the species that infect the gastrointestinal tract of man and that environmental contamination occurs by the spread of the spores contained in faeces, urine and other excretions. In foxes, domestic dogs and squirrels, it was observed that transplacental transmission is an important mechanism of spread of the disease (Bern, 2005; Weiss, 2001).

Although microsporidia spores are resistant to the environment, can be inactivated when exposed for 30 minutes at $70 \%$ alcohol, $1 \%$ formaldehyde or hydrogen peroxide $1 \%$ as well as when they are autoclaved for 10 minutes at $120^{\circ} \mathrm{C}$ (Méténier \& Vivarès, 2001).

The phenotypic and genotypic differences among strains of Encephalitozoon cuniculi can be used to indicate the main sources of infection for man. The lack of a specific host, coupled with the fact that the primate is susceptible to encephalitozoonosis suggests that man can become infected when exposed to an infected animal (Bern, 2005). 
The possibility that microsporidiosis is a zoonotic disease is still obscure. However, one must consider that these primitive protozoa have great capacity to adapt, since they are distributed among different groups of invertebrates and vertebrates (Didier, 2005).

Transmission of invertebrate microsporidia to humans has been considered impossible. This hypothesis is based on the temperature differences between the two classes of animals. However, Trammer et al. (1997) obtained infection of athymic mice inoculated with Nosema algerae, one of Microsporidian of the culicids. These results demonstrate for the first time it is possible the development of invertebrate microsporidia in mammalian hosts. Therefore, one should consider the possibility that invertebrates may be sources of infection for human microsporidiosis.

Diarrhea is the most frequent health problem caused by microsporidia, mainly in immunocompromised people. Waterborne transmission of microsporidia spores has not yet been appropriately addressed in epidemiological studies, due to the small size of spores. Their presence have been associated with waterborne outbreaks and also with recreational and river water (Fournier et al., 2000; Izquierdo et al., 2011).

Several drugs have been used to treat microsporidiosis. Fumagillin was the first drug to have effective results in the control of Nosema apis and was subsequently described as a broad-spectrum drugs to combat various species of microsporidia that parasitise insects. This drug has managed to control the multiplication of E. cuniculi in vitro and has been effective in the treatment of ocular infection by E. hellen in HIV-positive (Mathis, 2000).

Other active ingredients have been used to combat the microsporidia of invertebrates and small vertebrates. However, there are few drugs licensed for human use. Albendazol seems to be the most appropriate drug to combat infection by microsporidia (Bern, 2005; Weiss, 2001).

Measures aimed at preventing infection by microsporidia are not specific, since the mode of transmission and sources of infection for the disease remain uncertain. However, as the transmission of this parasite appears to be based on the ingestion of spores from feces and urine, preventive measures aimed at controlling the intake of them. In hospital settings precautions with body fluids, and good personal hygiene of infected individuals. These measures are particularly important for the prevention of eye infection, which results from hands and fingers contaminated by spores of respiratory fluids or urine (Didier, 2005).

The infective potential of the spores can only be evaluated in vitro for species that grow in cell culture. Experimental studies show that microsporidia spores can survive for months or years, depending on humidity and temperature, due to their chitin wall. Disinfectants usual, the simple boiling and autoclaving can kill the spores (Weiser,2005).

\section{Relationship between deforestation and the perpetuation of the parasites and enviromental}

Deforestation and ensuing changes in landuse, human settlement, commercial development, construction of roads, water control systems (dams, canals, irrigation systems, reservoirs), and climate singly and in combination have been accompanied by global increases in morbidity and mortality from a number of emergent parasitic diseases.

The nature and extent of change in the incidence of parasitic disease are affected by changes in landuse and settlement, the time interval from one landuse to another/others, changes in type of soil and its degree of water absorption, changes in vegetation characteristics, changes in the types and amounts of bodies of water, their size, shape, temperature, $\mathrm{pH}$, flow, movement, sedimentation and proximity to vegetation and, changes in climate (Table 6). 


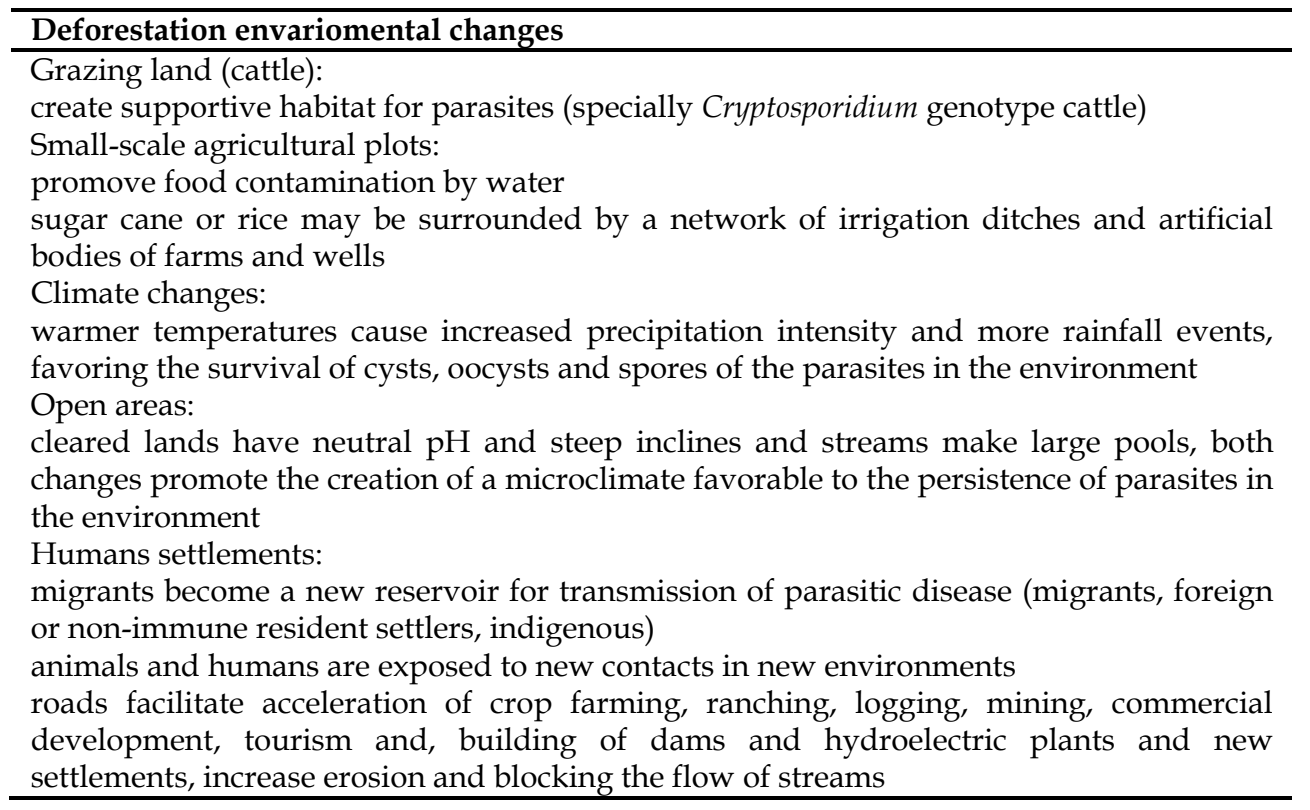

Table 6. Environmental changes caused by deforestation and its relationship with the emerging parasites.

\section{Conclusion}

Cryptosporidium, Giardia and microsporidia are single-celled, microscopic organisms and are disease-causing parasites that may infect people through contaminated drinking water and recreational waters. Symptoms resulting from infection include mild to severe diarrhea, abdominal cramps, weight loss, bloating, and vomiting. Chlorine, a commonly used disinfectant in water supplies, can not eliminate Giardia, Cryptosporidium or microsporidia from water sources. Rates of deforestation have grown explosively since the beginning of the twentieth century. Driven by local to global demand for agricultural and forest products and expanding human population centers, large swaths of species-rich tropical and temperate forest, and prairies, grasslands, and wetlands, have been converted to specie-poor agriculatural and ranching areas. The global rate of tropical deforestation is continuing at staggering levels well into this decade, with more than $2.3 \%$ of humid tropical forests cleared between 2000 and 2005 alone. Parallel to this habitat destruction is an exponential growth in human-wildlife interaction and conflict, which has resulted in exposure to new pathogens for humans, livestock, and wildelife. This way, we can conclude that deforestation can contribute to transmission of waterborne diseases.

\section{Reference}

Abreu-Acosta, N. et al. (2005). Enterocytozoon bieneusi (microsporidia) in clinical samples from immunocompetent individuals in Tenerife, Canary Islands, Spain. Trans. Royal Soc. Trop. Med. Hyg., Vol. 99, pp. 848-855. 
Barr, S.C. (1998). Cryptosporidiosis and cyclosporidiosis. In: Infectious diseases of the dog and cat. GREENE, C.E., pp.518-524, W B Saunders, Philadelphia.

Bern, C. et al. (2005). The epidemiology of intestinal microsporidiosis in patient with HIVAIDS in Lima, Peru. J. Infec. Dis., Vol.191, pp.1658-64.

Bogitsh, B.; Cheng, T.C. (1998). Human parasitology. pp. 210. Academic Press, San Diego.

Broglia, A.; Kapel, C. (2011) Changing dietary habits in a changing world: emerging drivers for the transmission of foodborne parasitic zoososes. Vet. Parasitol., Vol.182, pp.2-13.

Cacció, S.M.; Ryan, U. (2008). Molecular epidemiology of giardiasis. Mol. Biochem. Parasitol, Vol.160, pp.75-80.

Carey, C.M. et al. (2004). Biolgy, persistence and detection of Cryptosporidium parvum and Cryptosporidium hominis oocysts. Water Research, Vol.38, pp.818-862.

Chalmers, R.M.; Davies, A.P. (2009). Minireview: clinical cryptosporidiosis. Exp. Parasitol. Vol.76, pp.1976-1979.

Didier, E.S. (2005) Microsporidiosis: an emerging and opportunistc infection in humans and animals. Acta Trop., Vol.94, pp.61-76.

Fayer, R. et al. (2000). Epidemiology of Cryptoporidium: transmission, detection and identification. Intern. J. Parasitol. Vol.30, p.1305-1322.

Fayer, R. (2010) Taxonomy and species delimitation in Cryptosporidium. Exp. Parasitol. Vol.124, pp.90-97.

Fayer, R. et. al. (2010) Crypstosporidium ubiquitum n. sp. in animals and humans. Vet. Parasitol. Vol.172, pp.23-32.

Fournier, S. et al. (2000). Detection of microsporidia in surface water: a one-year follow-up study. FEMS Immunol. Med. Microbiol., Vol.29, pp.95-100.

Hajdušek, O. et al. (2004). Molecular identification of Cryptosporidium spp. in animal and human hosts from the Czech Republic. Vet. Parasitol. Vol.122, pp.183-192.

Hopkins, R.M. et al. (1997). Ribossomal RNA sequencing reveals differences between the genotypes of Giardia isolates recovered from humans and dogs living in the same locality. J. Parasitol. Vol.83, pp.44-51.

Hunter, P.R.; Thompson, R.C.A. (2005). The zoonotic transmission of Giardia and Cryptosporidium. Int. J. Parasitol. Vol.35, pp.1181-1190.

Inpankaew, T. et al. (2007). Canine parasitic zoonoses and temple communities in Thailand. Southeast Asian J. Trop. Med. Public. Health. Vol.38, pp.247-255.

Izquierdo, F. et al. (2011). Detection of microsporidia in drinking water, wastewater and recreational rivers. Water Res., Vol. 45, pp. 4837-4843.

Jerlström-Hultqvist, J. et al. (2010). Is human giardiasis caused by different Giardia species? Gut Microbes. Vol.1, pp.379-382.

Kulda, J.; Nohýnková, E. (1995). Giardiasis in humans and animals. In: Parasitic protozoa. KREIER, J.P., Academic Press, pp.225-422, San Diego.

Malčeková, B. et al. (2010). Seroprevalecne of antibodies to Encephalitozoon cuniculi and Encephalitozoon intestinalis in humans and animals. Res. Vet. Sci., Vol.89, pp.358-361.

Lallo, M.A. et al. (2002). Infecção experimental pelo Encephalitozoon cuniculi em camundongos imunossuprimidos com dexametasona. Rev. Saúde Pública, Vol.36, pp.621-626.

Lallo, M.A.; Bondan, E.F. (2005). Experimental meningoencephalomyelitis by Encephalitozoon cuniculi in cyclophosphamide-immunosuppressed mice. Arq. Neuro-Psiquiatr., Vol.63, pp.246-251.

Lallo M.A. et al. (2009). Ocorrência de Giardia, Cryptosporidium e microsporídios em animais silvestres em área de desmatamento no Estado de São Paulo, Brasil. Ciência Rural, Vol.39, pp.1465-1470. 
Marquardt, W.C. et al. (2000). Parasitology E vector biology. Haucourt Academic Press, pp. 205, San Diego.

Mathis, A. (2000). Microsporidia emerging advances in understanding the basis biology of these unique organism. Int. J. Parasitol., Vol.30, pp.795-804.

Méténier, G., Vivarès, P. (2001). Molecular characteristics and physiology of micrsporidia. Microbes and Infection, Vol. 3, pp.407-415.

Mohammed Mahdy, A.K. et al. (2008). Risk factors for endemic giardiasis: highlighting the possible association of contaminated water and food. Trans R. Soc. Trop. Med. Hyg., Vol.102, pp.465-470.

Monis, P.T.; Thompson, R.C.A. (2003). Cryptosporidium and Giardia-zoonoses: fact or fiction? Infect. Genet. Evol., Vol.3, pp.233-244.

Patz, J.A. et al. (2000). Effects of enviromental change on emerging parasitic diseases. Int. J. Parasitol., Vol.30, pp.1394-1405.

Pereira, A. et al. (2009). Ocorrência de microsporídios em pequenos mamíferos silvestres no Estado de São Paulo. Arq. Bras. Med. Vet. Zootec., Vol.61, pp.1474-1477.

Plutzer, J.; Karanis, P. (2009). Genetic polymorphism in Cryptosporidium species: an update. Vet. Parasitol., Vol.165, pp.187-199.

Robinson, G. et al. (2010). Re-description of Cryptosporidium cuniculus Inman and Takeuchi, 1979 (Apicomplexa: Cryptosporidiidae): morphology, biology and phylogeny. Intern. J. Parasitol., Vol.40, pp.1539-1548.

Rodriguez-Tovar, L.E. (2011). Fish microsporidia: Immune response, immunomodulation and vaccination. Fish $\mathcal{E}$ Shellfish Immunology, Vol.30, pp.999-1006.

Smith, H.V. et al. (2007). Cryptosporidium and Giardia as foodborne zoonoses. Vet. Parasitol., Vol.149, pp.29-40.

Slifko, T.R. et al. (2000). Emerging parasite zoonoses associated with water and food. Int. J. Parasitol., Vol.30, pp.1379-1393.

Theiller, M.; Breton, J. (2008). Enterocytozoon bieneusi in human and animals, focus on laboratory identification and molecular epidemiology. Parasite, Vol.15, pp.349-58.

Thompson, R.C.A. (2000). Giardiasis as a re-emerging infectious disease and its zoonotic potential. Int. J. Parasitol., Vol.30, pp.1259-1267.

Thompson, R.C.A. et al. (2008). The public health and clinical significance of Giardia and Cryptosporidium in domestic animals. Vet. J., Vol.177, pp.18-25.

Thompson, R.C.A. et al. (2009). Parasite zoonoses and wildlife: emerging issues. Int. J. Environ. Res. Public., Vol.6, pp.678-693.

Volotão, A.C. et al. (2007). Genotyping of Giardia duodenalis from human and animal samples from Brazil using beta-giardin gene: a phylogenetic analysis. Acta Trop., Vol.102, pp.10-19.

Weber, R. et al. (2002). Human microsporidial infections. Clin. Microbiol. Rev., Vol.7, pp.426-61.

Weiser, J. (2005). Microsporidia and the society for the invertebrate pathology: A personal point of view. J. Invert. Pathol., Vol.89, pp.12-18

Weiss, L.M. (2001). Microsporidia: emerging pathogenic protist. Acta Trop., Vol.78, pp.89-102.

Xiao, L. (2002). Host adaptation and host-parasite co-evolution in Cryptosporidium: implications for taxonomy and public health. Int. J. Parasitol., Vol.32, pp.1773-1785.

Xiao, L.; Fayer, R. (2008). Molecular characterization of species and genotypes of Cryptosporidium and Giardia and assessment of zoonotic transmission. Int. J. Parasitol., Vol.38, pp.1239-1255.

Xiao, L. (2010). Molecular epidemiology of cryptosporidiosis: an update. Experimental Parasitol., Vol.124, pp.80-89. 


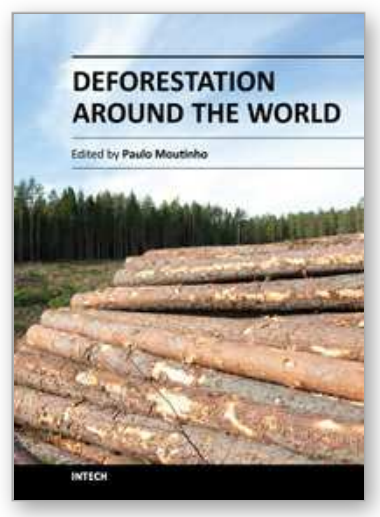

\author{
Deforestation Around the World \\ Edited by Dr. Paulo Moutinho
}

ISBN 978-953-51-0417-9

Hard cover, 372 pages

Publisher InTech

Published online 30, March, 2012

Published in print edition March, 2012

Deforestation and forest degradation represent a significant fraction of the annual worldwide human-induced emission of greenhouse gases to the atmosphere, the main source of biodiversity losses and the destruction of millions of people's homes. Despite local/regional causes, its consequences are global. This book provides a general view about deforestation dynamics around the world, incorporating analyses of its causes, impacts and actions to prevent it. Its 17 Chapters, organized in three sections, refer to deforestation impacts on climate, soil, biodiversity and human population, but also describe several initiatives to prevent it. A special emphasis is given to different remote-sensing and mapping techniques that could be used as a source for decision-makers and society to promote forest conservation and control deforestation.

\title{
How to reference
}

In order to correctly reference this scholarly work, feel free to copy and paste the following:

Maria Anete Lallo (2012). Deforestation and Water Borne Parasitic Zoonoses, Deforestation Around the World, Dr. Paulo Moutinho (Ed.), ISBN: 978-953-51-0417-9, InTech, Available from:

http://www.intechopen.com/books/deforestation-around-the-world/deforestation-and-waterborne-parasiticzoonoses

\section{INTECH}

open science | open minds

\section{InTech Europe}

University Campus STeP Ri Slavka Krautzeka 83/A 51000 Rijeka, Croatia Phone: +385 (51) 770447 Fax: +385 (51) 686166 www.intechopen.com

\author{
InTech China \\ Unit 405, Office Block, Hotel Equatorial Shanghai \\ No.65, Yan An Road (West), Shanghai, 200040, China \\ 中国上海市延安西路65号上海国际贵都大饭店办公楼405单元 \\ Phone: $+86-21-62489820$ \\ Fax: $+86-21-62489821$
}


(C) 2012 The Author(s). Licensee IntechOpen. This is an open access article distributed under the terms of the Creative Commons Attribution 3.0 License, which permits unrestricted use, distribution, and reproduction in any medium, provided the original work is properly cited. 